Research paper

\title{
An exploratory study of the heterogeneity of the jealousy phenomenon and its associations with affective temperaments and psychopathological dimensions in a large Brazilian sample
}

\author{
Amanda B. Lima ${ }^{\mathrm{a}}$, Cristiano A. Köhler ${ }^{\mathrm{a}}$, Brendon Stubbs ${ }^{\mathrm{b}, \mathrm{c}, \mathrm{d}}$, João Quevedo ${ }^{\mathrm{e}, \mathrm{f,g}, \mathrm{h}}$, Thomas \\ N. Hyphantis ${ }^{\mathrm{i}}$, Ai Koyanagi ${ }^{\mathrm{j}}$, Donatella Marazziti ${ }^{\mathrm{k}}$, Jair C. Soares ${ }^{\mathrm{f}}$, Eduard Vieta ${ }^{\mathrm{l}}$, André \\ F. Carvalho ${ }^{\mathrm{a}, *}$ \\ a Department of Clinical Medicine and Translational Psychiatry Research Group, Faculty of Medicine, Federal University of Ceará, Fortaleza, CE, Brazil \\ b Physiotherapy Department, South London and Maudsley NHS Foundation Trust, Denmark Hill, London SE5 8AZ, United Kingdom \\ ${ }^{\mathrm{c}}$ Health Service and Population Research Department, Institute of Psychiatry, Psychology and Neuroscience, King's College London, De Crespigny Park, \\ London Box SE5 8AF, United Kingdom \\ ${ }^{\mathrm{d}}$ Faculty of Health, Social care and Education, Anglia Ruskin University, Bishop Hall Lane, Chelmsford CM1 1SQ, United Kingdom \\ e Translational Psychiatry Program, Department of Psychiatry and Behavioral Sciences, McGovern Medical School, The University of Texas Health Science \\ Center at Houston (UTHealth), Houston TX, USA \\ ${ }^{\mathrm{f}}$ UT Center of Excellence on Mood Disorders, Department of Psychiatry and Behavioral Sciences, McGovern Medical School, The University of Texas Health \\ Science Center at Houston (UTHealth), Houston, TX, USA \\ ${ }^{\mathrm{g}}$ Neuroscience Graduate Program, The University of Texas Graduate School of Biomedical Sciences at Houston, Houston, TX, USA \\ ${ }^{\text {h }}$ Laboratory of Neurosciences, Graduate Program in Health Sciences, Health Sciences Unit, University of Southern Santa Catarina (UNESC), Criciúma, \\ Santa Catarina, Brazil \\ i Department of Psychiatry, Faculty of Medicine, School of Health Sciences, University of Ioannina, Greece \\ ${ }^{\mathrm{j}}$ Research and Development Unit, Parc Sanitari Sant Joan de Déu, Universitat de Barcelona, Fundació Sant Joan de Déu, CIBERSAM, Barcelona, Spain \\ k Dipartimento di Psichiatria, Neurobiologia, Farmacologia e Biotecnologie, University of Pisa, Italy \\ ${ }^{1}$ Bipolar Disorder Program, Department of Psychiatry and Psychology, Institute of Neuroscience, Hospital Clinic, University of Barcelona, IDIBAPS, \\ CIBERSAM, Barcelona, Catalonia, Spain
}

\section{A R T I C L E I N F O}

\section{Keywords:}

Affective temperaments

Personality

Jealousy

Psychiatry

Psychopathology

Survey

\begin{abstract}
A B S T R A C T
Background: Jealousy is a heterogenous emotion on a spectrum from normality to psychopathology. The relationship between different jealousy subtypes/dimensions and affective temperaments remain unknown. In addition, few large surveys have investigated the associations between jealousy subtypes and psychopathological dimensions.

Methods: A Brazilian Portuguese version of the "Questionario della Gelosia" (QUEGE) was developed. We obtained data from an anonymous web-based research platform. Socio-demographic data was obtained and participants answered the QUEGE, the TEMPS-Rio de Janeiro, and the Symptom Checklist-90-Revised (SCL-90-R).

Results: 2042 participants (29\% men, 71\% female, mean age + SD: $28.9 \pm 8.8$ years), took part in this survey. Confirmatory factor analysis provided a five-factor model for the QUEGE with self-esteem, paranoia, interpersonal sensitivity, fear of being abandoned, and obsessive dimensions. The anxious, irritable, cyclothymic, and depressive temperaments were independently associated with jealousy dimensions, whereas the hyperthymic temperament was associated with lower scores on the self-esteem jealousy dimension $(N=2042, \quad P<0.001)$. Jealousy subtypes were dissimilarly associated with SCL-90R psychopathological dimensions, whereas the 'obsessive' jealousy dimension was not significantly associated with SCL-90R dimension scores. We found no independent influence of gender across any jealousy dimension.

Limitations: A convenience web-based sample was employed. Cross-sectional design precludes the establishment of causal inferences.

Conclusions: Our data indicate that a five-factor solution may provide the best-fit model for the QUEGE. Different jealousy subtypes were independently associated with affective temperaments and psychopathological dimensions. These associations reported herein should be confirmed in prospective studies.
\end{abstract}

\footnotetext{
* Correspondence to: Department of Clinical Medicine, Faculty of Medicine, Federal University of Ceará, Rua Prof. Costa Mendes, 1608, $4^{\circ}$ andar, 60430-040 Fortaleza, CE, Brazil.

E-mail addresses: andrefc7@terra.com.br, andrefc7@hotmail.com (A.F. Carvalho).
} 


\section{Introduction}

Jealousy is a complex and common emotion, which involves cognitive, emotional and behavioral reactions related to the threat of losing a loved one to a real or imaginary rival (Kingham and Gordon, 2004; Pfeiffer and Wong, 1989). Jealousy may have a genetic influence and play an evolutionary role enabling the propagation of one's own genes in detriment of those of a true rival (Harris, 2003; Walum et al., 2013). In accordance to the evolutionary psychological perspective, sexual dimorphic reactions to infidelity may occur, with men predominantly reacting to sexual infidelity, while women would more intensely react to emotional infidelity (Harris, 2003). However, some scientists adopt a social cognitive perspective, and argue that sex differences in the expression of romantic jealousy do not exist or otherwise could be explained by stereotypes about how each gender becomes engaged in a romantic relationship (Carpenter, 2012; DeSteno and Salovey, 1996; Harris, 2003). In addition, it is worthy to note that cultural aspects may also influence the expression of jealousy (Bhugra, 1993).

The so-called pathological jealousy encompasses a heterogeneous set of conditions commonly encountered in clinical practice (Kingham and Gordon, 2004; Seeman, 1979). The definition of pathological jealousy has varied across different historical periods according to limits and norms of what manifestations would be acceptable or not (Mullen, 1991). Furthermore, it has become increasingly clear that pathological jealousy is not a unitary phenomenon, and may occur in a continuum from within a 'normal range' through to delusional jealousy (Kingham and Gordon, 2004; Mullen, 1991). Jealousy may be a burdensome manifestation of several psychopathological conditions including but not limited to affective disorders (Kingham and Gordon, 2004), obsessive-compulsive spectrum disorders (Marazziti et al., 2003a; Parker and Barrett, 1997), alcohol use disorders (DiBello et al., 2015; Michael et al., 1995), psychotic disorders (Seeman, 1979; Soyka et al., 1991; Soyka and Schmidt, 2011), and also as a neuropsychiatric disturbance in neurodegenerative diseases (e.g., Parkinson's disease) (Cipriani et al., 2012; Perugi et al., 2013).

There are no precise boundaries between "normal" and "pathological" jealousy, and identifying this demarcation has been an elusive, if not an impossible task (Docherty and Ellis, 1976; Marazziti et al., 2010b; Mullen and Martin, 1994). Therefore, a dimensional approach has been increasingly adopted and may aid in the understanding of jealousy (Elphinston et al., 2011; Marazziti et al., 2010a, 2003b, 2010b; Pfeiffer and Wong, 1989). Marazziti et al. (2010b) developed the "Questionario della Gelosia" which we will refer to as the Jealousy Questionnaire (JQ). The exploratory factor analysis of the JQ in a sample 500 Italian university students revealed five subtypes/dimensions of jealousy namely self-esteem, paranoia, interpersonal sensitivity, fear of being abandoned, and obsessionality (Marazziti et al., $2010 \mathrm{~b})$. This underlying factor structure is yet to be confirmed in an independent sample.

Relatively few studies have investigated personality constructs that could be associated with jealousy. Buunk (1997) found an association between three types of jealousy (reactive, preventive, and anxious) and neuroticism, social anxiety, rigidity and hostility in a sample of 100 Dutch male and female subjects recruited through a national television announcement. Low self-esteem has also been related to jealousy (Mathes et al., 1985; Stieger et al., 2012). Costa et al. (2015) found that a small sample of individuals with pathological jealousy presented with higher scores in novelty seeking and harm avoidance and lower scores on self-directedness and cooperativeness in Cloninger's temperament and character inventory (TCI) dimensions (Cloninger et al., 1994) relative to controls. In addition, individuals with pathological jealousy had elevated trait impulsivity (Costa et al., 2015).

Affective temperaments may represent a heritable and relatively stable aspect of personality (Rihmer et al., 2010). Based on previous work from Kraepelin (1921) and Kretschmer (1936), Akiskal and colleagues operationalized the concept of affective temperaments for research purposes with the definition of hyperthymic, cyclothymic, irritable, anxious, and depressive temperaments (Akiskal et al., 2005, 1998; Akiskal and Akiskal, 2005). Since then, accumulating evidence indicates that affective temperaments may influence creativity (Akiskal and Akiskal, 2007), and may also contribute to the emergence and modify the expression of affective disorders (Carvalho et al., 2013; Fountoulakis et al., 2016; Qiu et al., 2016), premenstrual dysphoric disorder (Camara et al., 2016), somatic symptoms (Hyphantis et al., 2013), and even suicidality (Baldessarini et al., 2016). Hence, the hyperthymic temperament may protect against suicidality, whereas the depressive temperament may increase suicidal risk (Serafini et al., 2011). To the best of our knowledge, no previous study has evaluated the association between affective temperaments and different subtypes/dimensions of jealousy.

The current study has three aims: (1) to develop a Brazilian Portuguese version of the JQ, and to investigate its factor structure in a large sample; (2) to explore associations between different jealousy dimensions and affective temperaments; and (3) to explore associations between psychopathological and jealousy dimensions.

\section{Methods}

\subsection{Sample selection}

Consecutive participants $(N=2153)$ were recruited through a large web-based Brazilian study (Portal Temperamento e Saúde Mental, www.temperamentoesaudemental.org). This website provides an encrypted and confidential platform for data collection, and was developed in a collaboration between the Federal University of Ceará (UFC) and the University of Fortaleza (UNIFOR). The research ethics committee of the Hospital Universitário Walter Cantídio approved the procedures for online data collection under the protocol number 1.058. 252. To access the surveys, participants were required to be at least 18 years old and asked to sign an electronic informed consent form. A number of validation questions throughout the protocol were employed to maximize the reliability of the data. This exploratory study included participants who had provided reliable responses to the attention and validation questions. From the initial sample, 2153 participants answered the complete survey. After quality review, 2042 subjects remained eligible and were included in the analyses (response rate: 94 . $8 \%)$. The mean \pm SD age of the participants was $28.9 \pm 8.8$ years. The sample predominantly comprised of women (71.0\%), while most participants were single (63.4\%). Table 1 summarizes sociodemographic characteristics of the sample.

This online survey collected sociodemographic data (age, gender, educational level, race, marital status, religious affiliation, occupation, and gross monthly income). In addition, this web-based platform included several validated psychological and psychiatric measures, including the jealousy questionnaire (JQ), the Temperament in Memphis Pisa and San Diego (TEMPS) instrument, and the Symptom-Checklist 90-Revised (SCL-90R). These measures are thoroughly described below.

\subsection{Development of the Brazilian version of the JQ}

A Brazilian Portuguese version of the JQ was developed in three steps: (1) translation from the original Italian version (Marazziti et al., 2010b) to Brazilian Portuguese by a bilingual mental health expert; (2) back-translation to Brazilian Portuguese by a bilingual mental health expert; and (3) semantic equivalence evaluation of the two versions by the author of the original instrument (DM). The version approved by the author was pre-tested in a convenience sample for transcultural adaptation $(N=25)$. This pilot study was conducted at the Porangabuçu campus of the UFC. Subjects were students and/or employees who had completed high school; each participant signed a written informed 
Table 1

Sociodemographic characteristics of the sample $(N=2042)$.

\begin{tabular}{|c|c|c|}
\hline Age, years (mean \pm SD) & 2042 & $28.9 \pm 8.8$ \\
\hline \multicolumn{3}{|l|}{ Gender $(n, \%)$} \\
\hline Female & 1449 & 71.0 \\
\hline Male & 593 & 29.0 \\
\hline \multicolumn{3}{|c|}{ Residence environment ( $n, \%)$} \\
\hline Urban & 2018 & 98.8 \\
\hline Rural & 24 & 1.2 \\
\hline \multicolumn{3}{|l|}{ Marital status (n, \%) } \\
\hline Single & 1295 & 63.4 \\
\hline Married & 369 & 18.1 \\
\hline Stable union & 186 & 9.1 \\
\hline Divorced & 84 & 4.1 \\
\hline Widowed & 6 & 0.3 \\
\hline Other & 102 & 5.0 \\
\hline \multicolumn{3}{|l|}{ Race $(n, \%)$} \\
\hline Caucasian & 854 & 41.8 \\
\hline African American & 140 & 6.9 \\
\hline Asian & 11 & 0.5 \\
\hline Mulatto $^{\mathrm{a}}$ & 923 & 45.2 \\
\hline Other & 114 & 5.6 \\
\hline \multicolumn{3}{|l|}{ Religion ( $n, \%)$} \\
\hline Catholic & 812 & 39.8 \\
\hline Protestant & 306 & 15.0 \\
\hline Spirit (Kardecism) & 165 & 8.1 \\
\hline Agnostic & 394 & 19.3 \\
\hline Other & 365 & 17.9 \\
\hline \multicolumn{3}{|l|}{ Educational level ( $n, \%)$} \\
\hline Incomplete elementary school & 3 & 0.2 \\
\hline Elementary school & 9 & 0.4 \\
\hline Incomplete high school & 35 & 1.7 \\
\hline High school & 201 & 9.8 \\
\hline Incomplete university degree & 921 & 45.1 \\
\hline University degree & 387 & 19.0 \\
\hline Post-graduate degree & 486 & 23.8 \\
\hline \multicolumn{3}{|l|}{ Employment status (n, \%) } \\
\hline Employed & 1048 & 51.3 \\
\hline Unemployed & 604 & 29.6 \\
\hline Housewife & 52 & 2.6 \\
\hline Retired & 22 & 1.1 \\
\hline Other & 316 & 15.5 \\
\hline \multicolumn{3}{|c|}{ Gross monthly income, USD ( $n, \%)$} \\
\hline Less than 307 & 648 & 31.7 \\
\hline $307-919$ & 600 & 29.4 \\
\hline $920-1839$ & 331 & 16.2 \\
\hline $1840-3066$ & 113 & 5.5 \\
\hline 3067 or above & 101 & 4.9 \\
\hline Unknown/Not informed & 249 & 12.2 \\
\hline
\end{tabular}

${ }^{a}$ Refers to an ethnic group of mixed white and black ancestry.

consent. The final version of the JQ is provided in the Supplementary material that accompanies the online version of this article.

\subsection{Measures}

Jealousy was assessed with the JQ, which measures the frequency, duration and presence of feelings and behaviors related to jealousy. This instrument comprises 30 self-reported questions, answered in a 4item Likert-dimension scale ranging from 1 (absence of feelings related to jealousy) to 4 (highest frequency or duration of those feelings). According to the original instrument jealousy is classified into 5 dimensions/subtypes: self-esteem/depressive jealousy, paranoia/paranoid jealousy, obsessionality/obsessive jealousy, fear of being abandoned/separation anxiety-related jealousy and interpersonal sensitivity (Marazziti et al., 2010b).
Affective temperaments were evaluated with the Brazilian Portuguese version of the Temperament Evaluation of Memphis, Pisa, Paris and San Diego (TEMPS-Rio de Janeiro) (Woodruff et al., 2011). The TEMPS-Rio de Janeiro was developed based on the original 110-version of the TEMPS-A (Akiskal et al., 2005), and comprises 45 true or false questions assessing the cyclothymic, hyperthymic, anxious, depressive and irritable temperaments.

We used the Brazilian Portuguese version of the Symptom Checklist-90-Revised inventory (SCL-90R) to assess psychopathological dimensions (Carissimi, 2011; Derogatis and Melisaratos, 1983). Briefly, the SCL-90 R is a 90-item 5-point Likert-type inventory, which assesses several psychopathological dimensions namely somatization, obsessive-compulsive, interpersonal sensitivity, depression, anxiety, hostility, phobic anxiety, paranoid ideation, and psychoticism.

\subsection{Statistical analysis}

All analyses were carried out using Stata MP version 14.0 for Windows (StataCorp, USA). Continuous variables are presented as means \pm standard deviations (SD). The Kolmogorov-Smirnov test was used to assess whether variables displayed a normal distribution. Categorical variables are presented as frequencies (\%).

Exploratory factor analysis was carried out to analyze the structure of the JQ. Principal component analysis (PCA) with Oblimin oblique rotation was used to extract the factors. The scree plot was used to determine the number factors; items with factor loadings $\geq 0.3$ were included in each factor (Johnson and Wichern, 2007). The factoriability of the correlation matrix was assessed with the Kaiser-MeyerOlkin (KMO) statistic and the Bartlett's test for sphericity.

Confirmatory factor analysis (CFA) was then performed. We tested 6 different models. One 5-factor model corresponds to the factor structure that we obtained in our exploratory PCA considering only the items with loading factors $>0.3$. For the second 5 -factor model, we considered all items of the JQ; the highest factor loading (in PCA) of the item defined its inclusion in a given dimension. For the other models, we did additional factor analyses extracting only one, two, three or four factors, and chose the dimension according to the highest factor loading. We estimated the goodness-of-fit of each model with the chi-square $\left(\chi^{2}\right)$, the comparative fit index (CFI), the root mean square error of approximation (RMSEA), and the standardized root mean square residual (SRMR). Although there is no absolute consensus in the literature, a RMSEA $\leq 0.06$, a SRMR $\leq 0.09$ and CFI $\geq 0.90$ are considered acceptable (Browne and Cudeck, 1993; Hu and Bentler, 1999). To compare the different models, the Akaike information criterion (AIC) was used. Models with the lowest AIC are judged to fit the data better than alternative solutions (Akaike, 1974).

The internal consistency of the JQ was measured using Cronbach's alpha coefficient for the whole instrument and for each individual dimension, with a value $\geq 0.7$ considered satisfactory (Nunnally and Bernstein, 1994).

The association of affective temperaments and the jealousy dimensions was evaluated using multiple linear regression models, adjusted by age, gender, and relationship status. Scores of each TEMPS temperament dimension were entered as predictor variables, and JQ dimension scores were the dependent (i.e., criterion) variables. Dimensional scores of the JQ comprised an average of individual items that loaded in each factor derived from PCA and CFA. Variance inflation factors (VIF) was used to check for multicollinearity, and values $<10$ were deemed adequate (all VIF values were $<10$; data available upon request). Associations between different jealousy subtypes and psychopathological dimensions were also assessed with separate multiple linear regression models, controlling for age, gender, and relationship status. Scores of each SCL-90R dimension were entered as dependent variables, while each jealousy dimension were entered as independent variables. Statistical significance was set at an alpha level of 0.05 . 


\section{Results}

\subsection{Psychometric properties of the $J Q$}

\subsubsection{Principal component analysis}

Using PCA, five factors were extracted according to the scree plot (Supplementary Fig. S1), accounting, respectively, for $15.5 \%, 14.9 \%$, $14.4 \%, 13.9 \%$, and $8.3 \%$ of the variance of JQ scores (overall $67.0 \%$ ). The KMO statistic (0.94) and the Bartlett's test of sphericity $(p<0.001)$ supported the factoriability of the JQ in our sample. Factor loadings of each individual item after Oblimin rotation are presented in Table 2. The first factor consisted of 6 items (1-6) and was considered as the 'obsessive' jealousy dimension. The second factor comprised 5 items of the JQ $(14,15,17-19)$ and was regarded as the 'self-esteem' jealousy dimension. The third factor included 5 items of the JQ (26-30) and comprised the 'paranoid' jealousy dimension. The fourth factor referred to the 'interpersonal sensitivity' dimension and comprised 5 items (7-11). The final factor was considered as 'fear of being abandoned/separation anxiety' jealousy dimension, and consisted of 4 items $(12,20-22)$. The items 13,16 and $23-25$ of the JQ did not load on any factor (i.e. factor loadings were all $<0.3$ ).

\subsubsection{Confirmatory factor analysis}

A 5-factor structure in which items with factor loadings $<0.3$ in PCA were excluded provided the best model to fit our data. This model had the lowest AIC and the most consistent fit indexes (Table 3).

\subsubsection{Internal consistency reliability}

The Brazilian Portuguese version of the JQ showed adequate internal consistency. Cronbach's alpha coefficient was 0.94 for the overall instrument, and 0.72-0.94 for each jealousy dimension/subtype.

\subsection{Associations of jealousy dimensions and affective temperaments}

Regression coefficients (standardized betas) for the associations of affective temperament dimensions and jealousy subtypes are presented in Table 4. The anxious and cyclothymic temperaments were independently associated with all jealousy dimensions. For the anxious temperament, the strongest association was with the 'obsessive' jealousy dimension. For the cyclothymic temperament, the strongest association was with the 'self-esteem' jealousy dimension. The hyperthymic temperament was negatively associated with the 'selfesteem' jealousy dimension. The irritable temperament was independently (and positively) associated with the 'obsessive', 'interpersonal sensitivity' and 'self-esteem' jealousy dimensions. The strongest associations were with the 'obsessive' and 'interpersonal sensitivity' dimensions. Finally, the depressive temperament was independently associated with the 'paranoid', 'obsessive', 'fear of being abandoned' and 'self-esteem' jealousy dimensions. The strongest association was with the 'self-esteem' dimension. There was no independent effect of gender on jealousy dimensions (Table 4). Educational level had no significant influence on any jealousy dimension. In addition, the inclusion of this variable did not increment the explanatory power of any of the multivariable models (data available upon request). Thus, we did not adjust our results for this variable.

\subsection{Association of jealousy subtypes and psychopathological dimensions}

Regression coefficients (standardized betas) for the associations of jealousy subtypes, controlling for age, gender, and relationship status and psychopathological dimensions are provided in Table 5. For this set of analysis, the sample comprised 1970 participants since 72 did not answer the SCL-90R. 'Paranoid' jealousy was independently associated with phobic anxiety, depression, hostility, obsessive-com- pulsive, paranoid ideation, psychoticism, and interpersonal sensitivity dimensions; association with paranoid ideation was the strongest. 'Obsessive' jealousy was not significantly associated with any SCL-90R dimension. 'Interpersonal sensitivity' jealousy was not independently associated with phobic anxiety, hostility, interpersonal sensitivity, and somatization dimensions. The 'fear of being abandoned' jealousy dimension was significantly associated with phobic anxiety, anxiety, depression, hostility, obsessive-compulsive, paranoid ideation, psychoticism, interpersonal sensitivity, and somatization dimensions; association was strongest with depression. The 'self-esteem' jealousy dimension was significantly and independently associated with all SCL$\mathrm{R}$ dimensions. Associations with the depression and interpersonal sensitivity dimensions were strongest (with beta values $>0.3$ ). The variable educational level had no significant effect on SCL-90R dimensions, and the inclusion of this variable did not improve the explanatory power of multivariable models (data available upon request).

\section{Discussion}

The present work confirms the proposed five-factor structure of the JQ in a large Brazilian sample. In addition, we found significant independent associations with different jealousy subtypes/dimensions with affective temperaments. Finally, our data suggest that different jealousy subtypes are dissimilarly associated with psychopathological dimensions.

\section{Table 2}

Factor loadings after oblimin rotation for the 5 extracted components. Only factor loadings with absolute values $\geq 0.30$ were retained.

\begin{tabular}{|c|c|c|c|c|c|}
\hline Item & PC1 & PC2 & PC3 & PC4 & PC5 \\
\hline 1 & 0.37 & & & & \\
\hline 2 & 0.41 & & & & \\
\hline 3 & 0.40 & & & & \\
\hline 4 & 0.43 & & & & \\
\hline 5 & 0.41 & & & & \\
\hline 6 & 0.39 & & & & \\
\hline 7 & & & & 0.36 & \\
\hline 8 & & & & 0.44 & \\
\hline 9 & & & & 0.46 & \\
\hline 10 & & & & 0.37 & \\
\hline 11 & & & & 0.30 & \\
\hline 12 & & & & & 0.30 \\
\hline \multicolumn{6}{|l|}{13} \\
\hline 14 & & 0.38 & & & \\
\hline 15 & & 0.38 & & & \\
\hline \multicolumn{6}{|l|}{16} \\
\hline 17 & & 0.45 & & & \\
\hline 18 & & 0.40 & & & \\
\hline 19 & & 0.46 & & & \\
\hline 20 & & & & & 0.48 \\
\hline 21 & & & & & 0.55 \\
\hline 22 & & & & & 0.47 \\
\hline \multicolumn{6}{|l|}{23} \\
\hline \multicolumn{6}{|l|}{24} \\
\hline \multicolumn{6}{|l|}{25} \\
\hline 26 & & & 0.43 & & \\
\hline 27 & & & 0.43 & & \\
\hline 28 & & & 0.43 & & \\
\hline 29 & & & 0.45 & & \\
\hline 30 & & & 0.46 & & \\
\hline Eigenvalue & 10.998 & 2.923 & 2.368 & 1.759 & 1.304 \\
\hline \% Variance explained & 15.5 & 14.9 & 14.4 & 13.9 & 8.3 \\
\hline Jealousy dimension & $\mathrm{O}$ & SE & $\mathrm{P}$ & IP & $\mathrm{F}$ \\
\hline
\end{tabular}

Abbreviations: $\mathbf{F}$ = fear of loss/separation-anxiety-related jealousy; IP = interpersonal sensitivity; $\mathbf{O}=$ obsessive jealousy; $\mathbf{P}=$ paranoid jealousy; $\mathbf{P C}=$ principal component; $\mathbf{S E}$ $=$ depressive/self-esteem jealousy. 
Table 3

Confirmatory factor analysis. Goodness-of-fit statistics for each model fitted against the sample data.

\begin{tabular}{|c|c|c|c|c|c|c|c|}
\hline Model & $\chi^{2}$ & df & $\chi^{2} / \mathbf{d f}$ & CFI & RMSEA (95\% CI) & SRMR & AIC \\
\hline 1-factor & $19,546.3$ & 405 & 48.3 & 0.527 & $0.152(0.000-$ undef $)$ & 0.112 & $138,885.9$ \\
\hline 2-factor & $13,085.0$ & 404 & 32.4 & 0.686 & $0.124(0.000-$ undef $)$ & 0.126 & $132,426.7$ \\
\hline 3-factor & 7044.5 & 402 & 17.5 & 0.836 & $0.090(0.088-0.092)$ & 0.077 & $126,390.2$ \\
\hline 4-factor & 4976.2 & 399 & 12.5 & 0.887 & $0.075(0.073-0.077)$ & 0.062 & $124,327.8$ \\
\hline 5-factor & 4389.1 & 395 & 11.1 & 0.901 & $0.070(0.069-0.072)$ & 0.058 & $123,748.8$ \\
\hline 5 -factor (loadings $>0.3$ ) & 2363.5 & 265 & 8.9 & 0.940 & $0.062(0.060-0.065)$ & 0.048 & $104,351.6$ \\
\hline
\end{tabular}

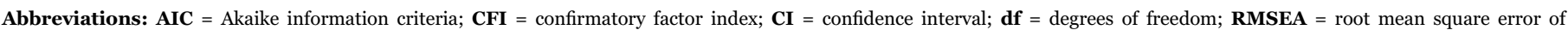
approximation; SRMR = standardized root mean square residual.

\subsection{The Brazilian Portuguese JQ and heterogeneity of jealousy}

The JQ was initially developed to measure different jealousy dimensions in general population samples (Marazziti et al., 2010b). An exploratory factor analysis carried out in a convenience sample of 500 Italian University students suggested an underlying five-factor structure for the JQ. Herein we developed a Brazilian Portuguese version of the JQ. Our data confirmed its five-factor structure in a larger sample. In CFA, a five-factor solution in which the five items $(13,16,23,24$, and 25) with loadings $<0.3$ in exploratory PCA yielded the best goodness of fit. Thus, these data suggest that a briefer 25 -item JQ could provide a valid measure to capture jealousy dimensions in Brazilian samples. In addition, adequate internal consistency reliabilities were verified for each jealousy dimension as well as the overall JQ score. We found no independent influence of gender in any jealousy dimension. Thus, these data do not provide support for sexually dimorphic reactions to infidelity as proposed by evolutionary psychology theorists (Harris, 2003). However, our sample was predominantly composed by single young woman. Therefore, this finding deserves confirmation in a sample with different sociodemographic characteristics.

\subsection{Associations of jealousy dimensions and affective temperaments}

Our results indicate that the hyperthymic temperament was not associated with jealousy. On the contrary, this temperament seemed to protect against 'self-esteem' jealousy. Certain characteristics of the hyperthymic temperament may explain these findings. Hyperthymic individuals are often cheerful, over-confident and self-assured (Akiskal and Akiskal, 2005). In addition, the hyperthymic temperament may be associated with elevated self-esteem (Masmoudi et al., 2015). The anxious and cyclothymic temperaments were associated with higher scores in all jealousy dimensions. The anxious temperament was more strongly related to 'obsessive' jealousy. This finding is consistent with 'worrying' about one's kin (Akiskal and Akiskal, 2005). Therefore, anxious individuals may predominantly express an 'obsessive-ruminative' jealousy dimension. 'Falling in and out love' is an acknowledged characteristic of cyclothymic persons (Akiskal et al., 1977; Akiskal and Akiskal, 2005). These individuals may engage in intense and unstable relationships. Furthermore, the cyclothymic temperament is also characterized by extreme mood reactivity to interpersonal and separation sensitivity (Perugi et al., 2015). Hence, the cyclothymic temperament was more closely related to the 'fear of being abandoned' jealousy. The depressive temperament was more strongly associated with the 'fear of being abandoned' and 'self-esteem' jealousy, which seem consistent with the view that individuals with this temperament find security with harmonious relationships with significant others (Akiskal and Akiskal, 2005; Ueki et al., 2004).

\subsection{Associations of jealousy subtypes and psychopathological dimensions}

Our data indicate that different jealousy dimensions are associated with psychopathology. Our results indicate that 'obsessive' jealousy may be less consistently associated with psychopathology. It is possible that the JQ had captured a more 'worrying-ruminative' aspect of jealousy closer to the 'normal' end of the jealousy spectrum, which may occur at a somewhat high frequency in individuals without obvious psychopathology. Our findings indicate that a dimensional (i.e., spectrum) approach to jealousy may be more appropriate than a dichotomous (normal versus pathological) perspective. However, different results could have emerged in a psychiatric (i.e., clinical population) population. For example, individuals with underlying personality disorder (such as paranoid personality disorder) could exhibit more severe forms of jealousy, with more obvious psychopathological implications.

In addition, the 'fear of being abandoned' and 'self-esteem' jealousy dimensions may be more consistently related to psychopathology. Furthermore, 'paranoid jealousy' was more strongly associated with

Table 4

Associations of affective temperaments and jealousy dimensions. Coefficients are presented for regression models of each TEMPS temperament scores.

\begin{tabular}{|c|c|c|c|c|c|}
\hline \multirow[t]{2}{*}{ Variable } & \multicolumn{5}{|c|}{ Jealousy dimension } \\
\hline & Paranoid & Obsessive & Interpersonal sensitivity & Fear of being abandoned & Self-esteem \\
\hline \multicolumn{6}{|l|}{ Affective temperaments } \\
\hline Anxious & $0.095(<0.001)$ & $0.151(<0.001)$ & $0.135(<0.001)$ & $0.079(0.001)$ & $0.117(<0.001)$ \\
\hline Hyperthymic & $0.006(0.787)$ & $-0.003(0.902)$ & $0.017(0.461)$ & $0.019(0.382)$ & $-0.094(<0.001)$ \\
\hline Irritable & $0.037(0.120)$ & $0.100(<0.001)$ & $0.157(<0.001)$ & $0.025(0.296)$ & $0.063(0.005)$ \\
\hline Cyclothymic & $0.094(<0.001)$ & $0.065(0.014)$ & $0.071(0.008)$ & $0.121(<0.001)$ & $0.120(<0.001)$ \\
\hline Depressive & $0.129(<0.001)$ & $0.083(0.002)$ & $0.026(0.354)$ & $0.245(<0.001)$ & $0.219(<0.001)$ \\
\hline In a relationship (0: No; 1 : Yes) & $-0.186(<0.001)$ & $0.004(0.839)$ & $0.040(0.074)$ & $-0.031(0.154)$ & $-0.128(<0.001)$ \\
\hline Gender (0: male; 1: female) & $-0.019(0.386)$ & $0.030(0.172)$ & $0.013(0.558)$ & $-0.033(0.130)$ & $-0.024(0.245)$ \\
\hline Age (years) & $0.004(0.866)$ & $-0.098(<0.001)$ & $-0.024(0.279)$ & $-0.033(0.127)$ & $-0.081(<0.001)$ \\
\hline Adjusted $R^{2}$ of the model & 0.114 & 0.110 & 0.088 & 0.145 & 0.241 \\
\hline Significance of $F$ change & $<0.001$ & $<0.001$ & $<0.001$ & $<0.001$ & $<0.001$ \\
\hline
\end{tabular}

Values presented as standardized beta coefficients ( $\mathrm{p}$ value).

Note: In a relationship (=1) includes participants who are married or on a stable relationship. Statistically significant results are in bold. 
psychoticism and paranoid ideation. These findings appear consistent with the hypothesis that individuals with high scores in this jealousy dimension may be more susceptible to present with delusional jealousy in the face of considerable distress. A previous study suggests that the DSM-IV-TR paranoid personality disorder could be a two-dimensional construct, including suspiciousness and hostility dimensions (Falkum et al., 2009). However, "accusations of infidelity of partner", which was related to the hostility dimension had poor indicator properties in this study. This diagnostic category (i.e., paranoid personality disorder) was removed from the 'Personality Disorders Chapter of the DSM-5' (Pull, 2013). Our findings suggest that 'paranoid jealousy' could be more dimensionally than categorically associated with suspiciousness in the general population. The 'interpersonal sensitivity' jealousy dimension seems similar to a condition referred to as "jealousie hyperestesique" a non-delusional form of jealousy also named "passionate jealousy" (Klein, 1954; Marazziti et al., 2010b), which may lie at the border between normal and pathological jealousy. Consistently, this jealousy subtype was more closely related to hostility and paranoid ideation.

\subsection{Strengths and limitations}

Some limitations of this study warrant consideration. First, we enrolled a convenience web-based sample, which may not be representative of the Brazilian population. Our survey had a predominance of young female participants. Second, the cross-sectional design of this study does not allow the establishment of causal inferences. In addition, our study was exploratory in nature. Third, the data herein obtained may not necessarily apply to other cultures. Strengths of this study include the enrollment of a relatively large sample, and the use of validated instruments. In addition, anonymous participation in the internet provides a setting with very low desirability bias to answer these instruments.

\subsection{Conclusions}

This study supports the notion that jealousy may be expressed in a heterogenous fashion in the general population. In addition, we found that the JQ may reliably quantify distinct facets of jealousy namely 'paranoid', 'obsessive', 'interpersonal sensitivity', 'fear of being abandoned', and 'self-esteem' dimensions. Jealousy dimensions were differently associated with affective temperaments. Finally, our findings indicate that jealousy may be better conceived as a dimensional phenomenon with psychopathological implications, but without clear borders demarcating 'normal' and 'pathological' jealousy. Prospective studies should be an important next step to elucidate directionality of the relationships we observed.

\section{Appendix A. Supporting information}

Supplementary data associated with this article can be found in the online version at doi:10.1016/j.jad.2017.01.022.

\section{References}

Akaike, H., 1974. A new look at the statistical model identification. IEEE Trans. Autom. Control 19, 716-723.

Akiskal, H.S., Akiskal, K.K., 2007. In search of Aristotle: temperament, human nature, melancholia, creativity and eminence. J. Affect. Disord. 100, 1-6.

Akiskal, H.S., Djenderedjian, A.M., Rosenthal, R.H., Khani, M.K., 1977. Cyclothymic disorder: validating criteria for inclusion in the bipolar affective group. Am. J. Psychiatry 134, 1227-1233.

Akiskal, H.S., Mendlowicz, M.V., Jean-Louis, G., Rapaport, M.H., Kelsoe, J.R., Gillin, J.C., Smith, T.L., 2005. TEMPS-A: validation of a short version of a self-rated instrument designed to measure variations in temperament. J. Affect. Disord. 85, 45-52.

Akiskal, H.S., Placidi, G.F., Maremmani, I., Signoretta, S., Liguori, A., Gervasi, R., Mallya, G., Puzantian, V.R., 1998. TEMPS-I: delineating the most discriminant traits of the cyclothymic, depressive, hyperthymic and irritable temperaments in a nonpatient population. J. Affect. Disord. 51, 7-19. 
Akiskal, K.K., Akiskal, H.S., 2005. The theoretical underpinnings of affective temperaments: implications for evolutionary foundations of bipolar disorder and human nature. J. Affect. Disord. 85, 231-239.

Baldessarini, R.J., Vazquez, G.H., Tondo, L., 2016. Affective temperaments and suicidal ideation and behavior in mood and anxiety disorder patients. J. Affect. Disord. 198, 78-82.

Bhura, D, 1993. Cross-cultural aspects of jealousy. Int Rev. Psychiatry 5, 271-280.

Browne, M.W., Cudeck, R., 1993. Alternative ways of assessing model fit. In: Bollen, K.A., Long, J.S. (Eds.), Testing Structural Equation Models.. Sage, Newbury Park, CA, $136-161$.

Buunk, B.P., 1997. Personality, birth order and attachment styles as related to various types of jealousy. Personal. Individ. Differ. 23, 997-1006.

Camara, R.A., Kohler, C.A., Maes, M., Nunes-Neto, P.R., Brunoni, A.R., Quevedo, J., Fernandes, B.S., Perugi, G., Hyphantis, T.N., Carvalho, A.F., 2016. Affective temperaments and emotional traits are associated with a positive screening for premenstrual dysphoric disorder. Compr. Psychiatry 71, 33-38.

Carissimi, A., 2011. Examinando fatores causais de sintomas psicologicos atraves do SCL-90 R em pacientes com apneia do sono grave (Master's degree dissertation). Universidade Federal do Rio Grande do Sul, Porto Alegre, Brazil.

Carpenter, C.J., 2012. Meta-analyses of sex differences in responses to sexual versus emotional infidelity men and women are more similar than different. Psychol. Women Q. 36, 25-37.

Carvalho, A.F., Hyphantis, T.N., Taunay, T.C., Macedo, D.S., Floros, G.D., Ottoni, G.L. Fountoulakis, K.N., Lara, D.R., 2013. The relationship between affective temperaments, defensive styles and depressive symptoms in a large sample. J. Affect. Disord. 146, 58-65.

Cipriani, G., Vedovello, M., Nuti, A., di Fiorino, A., 2012. Dangerous passion: othello syndrome and dementia. Psychiatry Clin. Neurosci. 66, 467-473.

Cloninger, C.R., Przybeck, T.R., Svrakic, D.M., 1994. The Temperament and Character Inventory (TCI): a guide to its development and use. Center for Psychobiology of Personality, Washington University St. Louis, MO.

Costa, A.L., Sophia, E.C., Sanches, C., Tavares, H., Zilberman, M.L., 2015. Pathologica jealousy: romantic relationship characteristics, emotional and personality aspects, and social adjustment. J. Affect. Disord. 174, 38-44.

Derogatis, L.R., Melisaratos, N., 1983. The brief symptom Inventory: an introductory report. Psychol. Med. 13, 595-605.

DeSteno, D.A., Salovey, P., 1996. Evolutionary origins of sex differences in jealousy? Questioning the "fitness" of the model. Psychol. Sci. 7, 367-372.

DiBello, A.M., Rodriguez, L.M., Hadden, B.W., Neighbors, C., 2015. The green eyed monster in the bottle: Relationship contingent self-esteem, romantic jealousy, and alcohol-related problems. Addict. Behav. 49, 52-58.

Docherty, J.P., Ellis, J., 1976. A new concept and finding in morbid jealousy. Am. J. Psychiatry 133, 679-683.

Elphinston, R.A., Feeney, J.A., Noller, P., 2011. Measuring romantic jealousy: validation of the multidimensional jealousy scale in Australian samples. Aust. J. Psychol. 63, $243-251$.

Falkum, E., Pedersen, G., Karterud, S., 2009. Diagnostic and statistical manual of mental disorders, fourth edition, paranoid personality disorder diagnosis: a unitary or a twodimensional construct? Compr. Psychiatry 50, 533-541.

Fountoulakis, K.N., Gonda, X., Koufaki, I., Hyphantis, T., Cloninger, C.R., 2016. The role of temperament in the Etiopathogenesis of bipolar spectrum illness. Harv. Rev. Psychiatry 24, 36-52.

Harris, C.R., 2003. Factors associated with jealousy over real and imagined infidelity: an examination of the social-cognitive and evolutionary psychology perspectives. Psychol. Women Q. 27, 319-329.

Hu, Lt, Bentler, P.M., 1999. Cutoff criteria for fit indexes in covariance structure analysis: conventional criteria versus new alternatives. Struct. Equ. Model.: a Multidiscip. J. 6, $1-55$.

Hyphantis, T.N., Taunay, T.C., Macedo, D.S., Soeiro-de-Souza, M.G., Bisol, L.W., Fountoulakis, K.N., Lara, D.R., Carvalho, A.F., 2013. Affective temperaments and ego defense mechanisms associated with somatic symptom severity in a large sample. J. Affect. Disord. 150, 481-489.

Johnson, R.A., Wichern, D.W., 2007. Applied Multivariate Statistical Analysis 6th ed. Pearson Prentice Hall, Upper Saddle River, NJ.

Kingham, M., Gordon, H., 2004. Aspects of morbid jealousy. Adv. Psychiatr. Treat. 10, 207-215.

Klein, R., 1954. The psychoses of passion (les psychoses Passionnelles). Br. J. Psychiatry $100,(759-759)$

Kraepelin, E., 1921. Manic Depressive Insanity and Paranoia. E \& S Livingstone,
Edingburgh.

Kretschmer, E., 1936. Psychique und Character. Kegan, Paul, Trench, Trubner and Co. Ltd., London UK.

Marazziti, D., Consoli, G., Albanese, F., Laquidara, E., Baroni, S., Catena Dell'osso, M., 2010a. Romantic attachment and subtypes/dimensions of jealousy. Clin. Pr. Epidemiol. Ment. Health 6, 53-58.

Marazziti, D., Di Nasso, E., Masala, I., Baroni, S., Abelli, M., Mengali, F., Mungai, F., Rucci, P., 2003a. Normal and obsessional jealousy: a study of a population of young adults. Eur. Psychiatry.: J. Assoc. Eur. Psychiatr. 18, 106-111.

Marazziti, D., Rucci, P., Di Nasso, E., Masala, I., Baroni, S., Rossi, A., Giannaccini, G., Mengali, F., Lucacchini, A., 2003b. Jealousy and subthreshold psychopathology: a serotonergic link. Neuropsychobiology 47, 12-16.

Marazziti, D., Sbrana, A., Rucci, P., Cherici, L., Mungai, F., Gonnelli, C., Massimetti, E., Raimondi, F., Doria, M.R., Spagnolli, S., Ravani, L., Consoli, G., Catena Dell Osso, M., 2010b. Heterog. jealousy Phenom. Gen. Popul.: Ital. Study CNS Spectr. 15, 19-24.

Masmoudi, J., Trigui, D., Feki, I., Baati, I., Jaoua, A., 2015. Athletic performance, selfesteem and temperamental profile: which relationship? La Tunis. Med. 93, 175-180.

Mathes, E.W., Adams, H.E., Davies, R.M., 1985. Jealousy: loss of relationship rewards, Loss of self-esteem, depression, anxiety, and anger. J. Personal. Soc. Psychol. 48, 1552.

Michael, A., Mirza, S., Mirza, K.A., Babu, V.S., Vithayathil, E., 1995. Morbid jealousy in alcoholism. Br. J. Psychiatry.: J. Ment. Sci. 167, 668-672.

Mullen, P.E., 1991. Jealousy: the pathology of passion. Br. J. Psychiatry.: J. Ment. Sci. $158,593-601$.

Mullen, P.E., Martin, J., 1994. Jealousy: a community study. Br. J. Psychiatry.: J. Ment. Sci. 164, 35-43.

Nunnally, J.C., Bernstein, I.H., 1994. Psychometric theory. McGraw-Hill, New York.

Parker, G., Barrett, E., 1997. Morbid jealousy as a variant of obsessive-compulsive disorder. Aust. N.Z. J. Psychiatry 31, 133-138.

Perugi, G., Hantouche, E., Vannucchi, G., Pinto, O., 2015. Cyclothymia reloaded: a reappraisal of the most misconceived affective disorder. J. Affect. Disord. 183 , 119-133.

Perugi, G., Poletti, M., Logi, C., Berti, C., Romano, A., Del Dotto, P., Lucetti, C., Ceravolo, R., Dell'Osso, L., Bonuccelli, U., 2013. Diagnosis, assessment and management of delusional jealousy in Parkinson's disease with and without dementia. Neurol. Sci.: Off. J. Ital. Neurol. Soc. Ital. Soc. Clin. Neurophysiol. 34, 1537-1541.

Pfeiffer, S.M., Wong, P.T., 1989. Multidimensional jealousy. J. Soc. Pers. Relat. 6 , $181-196$.

Pull, C.B., 2013. Too few or too many? Reactions to removing versus retaining specific personality disorders in DSM-5. Curr. Opin. Psychiatry 26, 73-78.

Qiu, F., Akiskal, H.S., Kelsoe, J.R., Greenwood, T.A., 2016. Factor analysis of temperament and personality traits in bipolar patients: correlates with comorbidity and disorder severity. J. Affect. Disord. 207, 282-290.

Rihmer, Z., Akiskal, K.K., Rihmer, A., Akiskal, H.S., 2010. Current research on affective temperaments. Curr. Opin. Psychiatry 23, 12-18.

Seeman, M.V., 1979. Pathological jealousy. Psychiatry 42, 351-361.

Serafini, G., Pompili, M., Innamorati, M., Fusar-Poli, P., Akiskal, H.S., Rihmer, Z., Lester, D., Romano, A., de Oliveira, I.R., Strusi, L., Ferracuti, S., Girardi, P., Tatarelli, R., 2011. Affective temperamental profiles are associated with white matter hyperintensity and suicidal risk in patients with mood disorders. J. Affect. Disord. $129,47-55$.

Soyka, M., Naber, G., Volcker, A., 1991. Prevalence of delusional jealousy in different psychiatric disorders. An analysis of 93 cases. Br. J. Psychiatry.: J. Ment. Sci. 158, 549-553.

Soyka, M., Schmidt, P., 2011. Prevalence of delusional jealousy in psychiatric disorders J. Forensic Sci. 56, 450-452.

Stieger, S., Preyss, A.V., Voracek, M., 2012. Romantic jealousy and implicit and explicit self-esteem. Personal. Individ. Differ. 52, 51-55.

Ueki, H., Holzapfel, C., Sakado, K., Washino, K., Inoue, M., Ogawa, N., 2004. Dimension of Typus melancholicus on Kasahara's Inventory for the Melancholic Type Personality. Psychopathology 37, 53-58.

Walum, H., Larsson, H., Westberg, L., Lichtenstein, P., Magnusson, P.K., 2013. Sex differences in jealousy: a population-based twin study in Sweden. Twin Res. Hum. Genet.: Off. J. Int. Soc. Twin Stud. 16, 941-947.

Woodruff, E., Genaro, L.T., Landeira-Fernandez, J., Cheniaux, E., Laks, J., Jean-Louis, G., Nardi, A.E., Versiani, M.C. Akiskal, H.S., Mendlowicz, M.V., 2011. Validation of the Brazilian brief version of the temperament auto-questionnaire TEMPS-A: the brief TEMPS-Rio de Janeiro. J. Affect. Disord. 134, 65-76. 